\title{
Imported diphyllobothriasis in Switzerland: molecular methods to define a clinical case of Diphyllobothrium infection as Diphyllobothrium dendriticum, August 2010
}

F de Marval' ${ }^{1}$, B Gottstein ${ }^{2}$, M Weber $^{3}$, B Wicht (barbarawicht@yahoo.it) 4

1. Dianalabs, Geneva, Switzerland

2. Institute of Parasitology, University of Bern, Bern, Switzerland

3. Private practice, Chêne-Bourg, Switzerland

4. Istituto cantonale di microbiologia, Bellinzona, Switzerland

Citation style for this article:

de Marval F, Gottstein B, Weber M, Wicht B. Imported diphyllobothriasis in Switzerland: molecular methods to define a clinical case of Diphyllobothrium infection as Diphyllobothrium dendriticum, August 2010. Euro Surveill. 2013;18(3):pii=20355. Available online: http://www.eurosurveillance.org/ViewArticle. aspx?Articleld $=20355$

Article submitted on 07 May 2012 / published on 17 January 2013

Following a first clinical case of infection by Diphyllobothrium dendriticum in Switzerland in 2006, we report a second case in the country. The species was identified by molecular methods. In the Swiss, French and Italian subalpine regions, human diphyllobothriasis has seen a comeback since the late 1980's, and Diphyllobothrium latum is usually considered the causative agent of the disease. In addition, several locally acquired and imported clinical infections due to allochthonous Diphyllobothrium species have been documented in the last years. Due to the colonisation potential of these parasites and their probably underestimated presence in the human population, there is a need for discriminating them at the medical laboratory level. Because the morphological characters are very similar among the different taxa, a correct identification requires the use of molecular methods. Molecular identification would improve diagnosis and help monitor the distribution of Diphyllobothrium species in Europe.

\section{Introduction}

Diphyllobothriasis is due to tapeworms of the genus Diphyllobothrium and is acquired through the consumption of raw or poorly cooked freshwater fish. In distinct stages of their life cycle, Diphyllobothrium spp. occupy different host species. The eggs present in the water are ingested by small crustaceans, such as copepods, constituting the first intermediate hosts in which they develop to a larval stage. As crustaceans are predated by fish, fish become the second intermediate hosts where Diphyllobothrium larvae further develop. The definite hosts are fish eating mammals (including humans) or birds, where Diphyllobothrium matures into an adult stage.

Human diphyllobothriasis is often a mild illness: about half of the patients are asymptomatic, while the others mostly suffer from minor discomforts, such as diarrhoea, abdominal pain and digestive troubles. Rare cases of megaloblastic anaemia associated with vitamin B12 deficiency have been reported in the literature [1].

Globally, the incidence of human diphyllobothriasis has decreased in the last 20 years, particularly in northern and eastern Europe [2]. Nevertheless, in some Swiss, French and Italian subalpine regions the disease has seen a comeback, as shown by the more than 530 cases reported since 1987 from around lakes Leman (Geneva), Morat, Bienne, Maggiore, Lario (Como), Iseo and Garda [2]. In these areas, the species Diphyllobothrium latum is considered the causative agent of diphyllobothriasis. However, infections due to allochthonous species (D. nihonkaiense, $D$. dendriticum) have been recently documented [3-7]. A first clinical case due to $D$. dendriticum was diagnosed in 2006 in Switzerland, raising the question of potential transmission to susceptible intermediate hosts present in the local environment [4]. In this report, we describe a second case of symptomatic infection by $D$. dendriticum in Switzerland. Confirmation of the species was done by molecular identification.

A four year-old boy expelled tapeworm segments in stool, 12 days after returning from a 15-day holiday travel in Singapore and Bali in August 2010. He had been suffering from abdominal pains (cramps) and loose stools since his return to Switzerland. Standard laboratory procedures held in the clinical laboratory (Dianalabs) led to the identification of Diphyllobothrium spp., based upon the presence of typical operculated eggs in segments. However, because of the unusual shape of a tapeworm proglottid (longer than wide as if stretched, with an excentred uterus) and the possible Asian origin of infection, the specimen was preserved in $70^{\circ}$ ethanol and sent to the Institute of Parasitology in Bern and to the Cantonal Institute of Microbiology in Bellinzona, where it was identified as $D$. dendriticum by molecular methods. 
Mebendazole was first administered to the patient, with no curative effect, as confirmed by the persisting presence of eggs in stool after three weeks. The patient was then re-medicated with praziquantel and recovered promptly. No parasites were found upon stool testing six weeks after praziquantel therapy.

The patient's family did not present with symptoms and underwent no further investigation, except for the seven year-old patient's sister who was checked for intestinal parasites but found negative.

\section{Methods}

The faecal specimen was processed by standard sedimentation technique [8] to concentrate putatively present Diphyllobothrium eggs and subsequently assess these by light microscopy. A segment of proglottids of approximately $5 \mathrm{~cm}$ length was processed for staining with lacto-acetic carmine according to Rukhadze and Blajin [9].

Genomic DNA from about $50 \mathrm{mg}$ of proglottid tissue was extracted with the DNeasy Blood and Tissue Kit (Qiagen). Polymerase chain reaction (PCR) was performed using the Taq PCR Master Mix Kit (Qiagen) with primers targeting a region of the $5.8 \mathrm{~S}$ ribosomal RNA (5.8S rRNA) comprising internal transcribed spacers (ITS) 1 and 2 [10], the 18S ribosomal RNA (18S rRNA) [11] and the cytochrome c oxidase subunit 1 gene (cox1) $[3,12]$ sequences. The amplification of all targets was carried out under the following conditions: $5 \mathrm{~min}$ at $94^{\circ} \mathrm{C}, 35$ cycles consisting of $30 \mathrm{~s}$ at $94^{\circ} \mathrm{C}, 40 \mathrm{~s}$ at $45^{\circ} \mathrm{C}, 1 \mathrm{~min}$ at $72{ }^{\circ} \mathrm{C}$, and a final extension step of 10 min at $72^{\circ} \mathrm{C}$. Amplicons were visualised by electrophoresis in a $0.8 \%$ agarose gel containing ethidium bromide, and purified through Sephadex G-50 columns (GE Healthcare). DNA was quantified with a ND-100 Spectrophotometer (NanoDrop Technologies Inc.). Sequencing was performed with the BigDye Terminator Cycle Sequencing Ready Reaction kit (Applied Biosystems), according to the provider's recommendations. Samples were purified by osmosis with $0.025 \mu \mathrm{m}$ nitrocellulose filters (Millipore) in tris ethylenediaminetetraacetic acid (TE) buffer $\mathrm{pH} 8$ for two hours. Eight $\mu \mathrm{l}$ of purified solution were placed in $0.5 \mathrm{ml}$ Genetic Analyzer Sample Tubes with $12 \mu \mathrm{l} \mathrm{Hi-Di} \mathrm{Formamide}$ (Applied Biosystems). Samples were then loaded in an automated sequencing system (ABI PRISM 310 Genetic Analyzer; Perkin Elmer).

Sequence electropherograms were corrected by using the software EditSeq (DNASTAR Inc.). Their identity was first checked by basic local alignment search tool (BLAST) [13]. Sequence fragments of 657 and 375 nucleotides in length, derived from the PCRs targeting the ITS1-5.8SrRNA and cox1 genes were then respectively compared to representative ITS1-5.8SrRNA or cox1 sequences from different Diphyllobothrium spp. by pairwise and multiple alignments using ClustalW [14] with the software Molecular Evolutionary Genetics Analysis (MEGA) version 4.0 [15]. Phylogenetic trees (neighbour-joining method; Kimura-2 parameters; bootstrap test for 500 replicates) were subsequently inferred from the alignments.

\section{Results}

Microscopical analyses of the coprological sediment revealed the presence of oval-shape unembryonated eggs (mean size: $49 \times 64 \mu \mathrm{m}$; range: $48.5-52.5 \times 62.5^{-}$ $70 \mu \mathrm{m})$, characterised by the presence of a hardly visible operculum and a small knob at the abopercular end (Figure 1).

Microscopical analyses of the stained proglottids revealed the presence of only one set of reproductive organs per proglottid (Figure 2). The central uterine structure showed several rosette-shaped loops. Morphological criteria matched to those described

\section{FIGURE 1}

Diphyllobothrium dendriticum eggs recovered from a patient stool, Switzerland, 2010

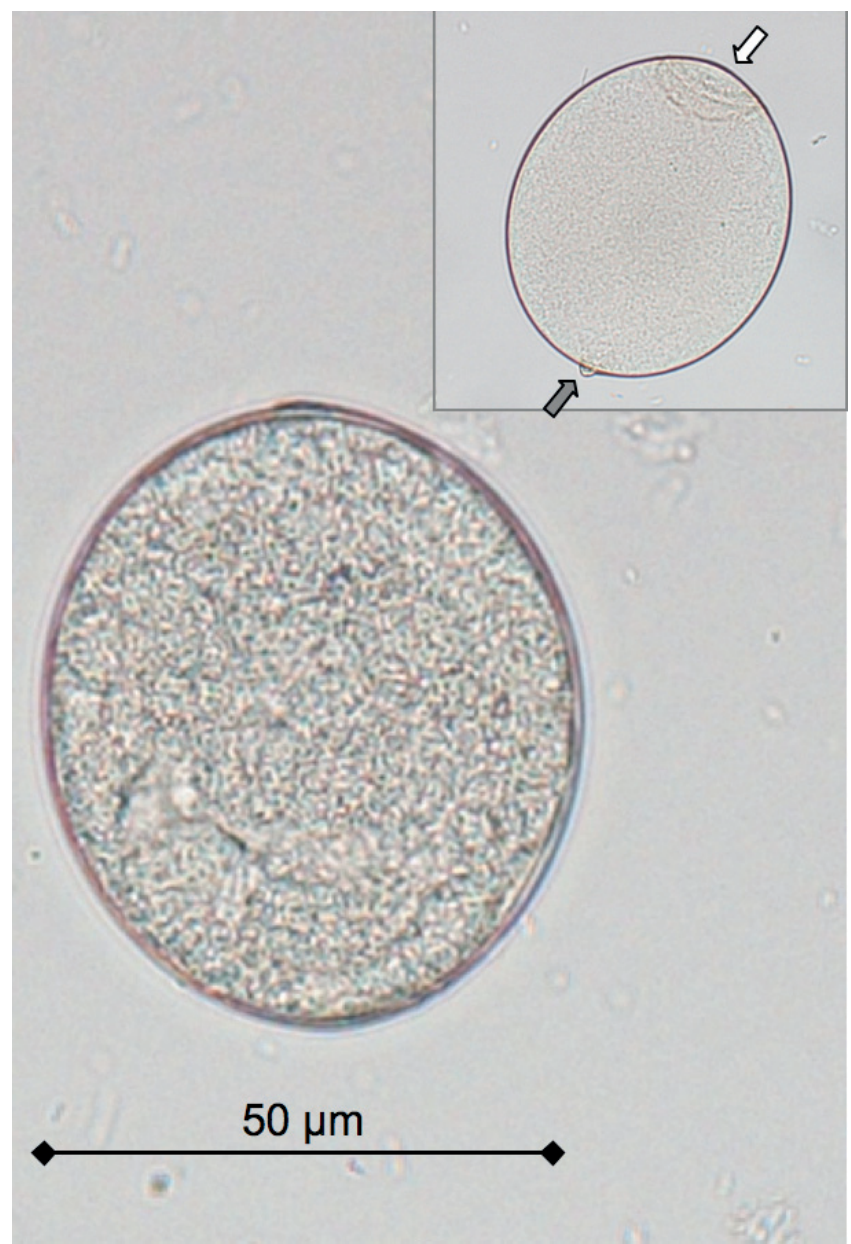

White arrow: operculum; grey arrow: knob.

The pictures were taken under $400 x$ magnification and the mean size of the eggs was $49 \times 64 \mu \mathrm{m}$. 


\section{FIGURE 2}

Diphyllobothrium dendriticum segment recovered from a patient stool, Switzerland, 2010

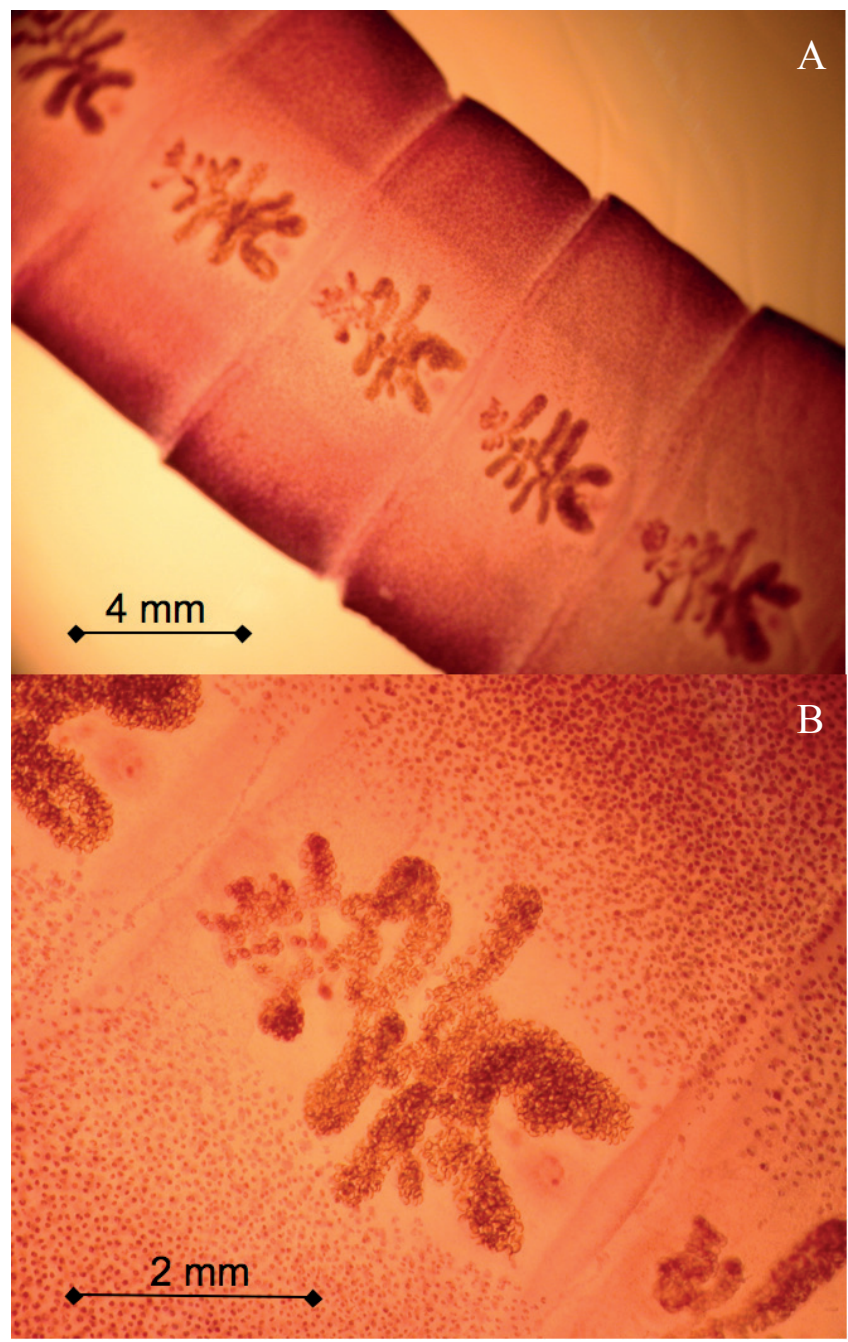

A. Diphyllobothrium dendriticum segment.

B. Enlargement of an individual proglottid where the central uterine structure forms several rosette-shaped loops.

for Diphyllobothrium spp. [16], while a species-specific identification was not possible based upon morphology.

The nucleotide sequences of the ITS1-5.8S rRNA, 18S rRNA and cox1 derived from the Diphyllobothrium affecting the patient were deposited in public databases and are available in the European Molecular Biology Laboratory (EMBL), GenBank and DNA Data Bank of Japan (DDJB) databases under accession numbers HQ682065, HQ682066 and HQ682067. Due to technical problems, the sequence of ITS2 was not fully obtained and therefore not used in the analysis.
The results of BLAST search showed that all the sequenced targets respectively reached $\geq 99 \%$ identity (highest scores) at the nucleotide level with $D$. dendriticum homologous reference sequences of respective GenBank accession numbers FM204787 (ITS1-5.8S rRNA), DQ768164, DQ181945 (18S rRNA) and AM412738 (cox1). The $18 \mathrm{~S}$ rRNA sequence also showed $99 \%$ identity with those of $D$. ditremum (GenBank accession numbers: DQ768165, DQ181944) and D. latum (GenBank accession number: DQ316795).

The position of the sample sequences of ITS1-5.8S rRNA and cox1 regions in the phylogenetic trees confirmed the Diphyllobothrium spp.affecting the patient as $D$. dendriticum (Nitsch, 1824) (Figures 3 and 4). The phylogenetic tree built on the basis of $18 \mathrm{~S}$ rRNA sequences is not shown, because this target is not useful for the discrimination of $D$. dendriticum from other species [2].

\section{Discussion}

At the time of tapeworm evacuation, the patient was known to have had a meal in a Japanese restaurant in Singapore (on day 4 of his journey) where the family had consumed various dishes (fish, chicken). According to the recollection of the family members, the meal did not contain raw fish. Retrospective investigations revealed that the patient regularly consumed fish, e.g. smoked salmon with pasta at home. This salmon was always bought in the same department store in France and was of the same brand. According to the product information, it belonged to the species Salmo salar, was farmed in Norway, smoked in France and guaranteed 'never frozen'. The homemade sauce was made by dropping slices of smoked salmon into boiling cream

\section{FIGURE 3}

Neighbour-joining tree based on $5.8 \mathrm{~S}$ ribosomal RNA internal transcribed spacer 1 sequences, to determine the Diphyllobothrium species affecting a patient, Switzerland, 2010

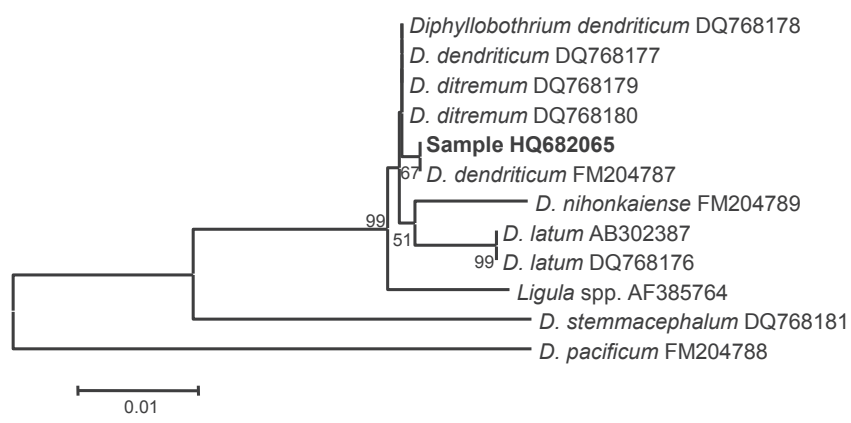

The tree is based on $5.8 \mathrm{~S}$ ribosomal RNA internal transcribed spacer 1 (5.8S rRNA-ITS1) sequence fragments of 657 bp. The 'sample' refers to the sequence of the unknown Diphyllobothrium spp. affecting the patient. GenBank accession numbers of all the sequences used to construct the tree are indicated. On the tree nodes, Kimura-2 parameters bootstrap values $>50$ for 500 replicates are shown. 


\section{FIGURE 4}

Neighbour-joining tree based on cytochrome c oxidase subunit 1 sequences, to determine the Diphyllobothrium species affecting a patient, Switzerland, 2010

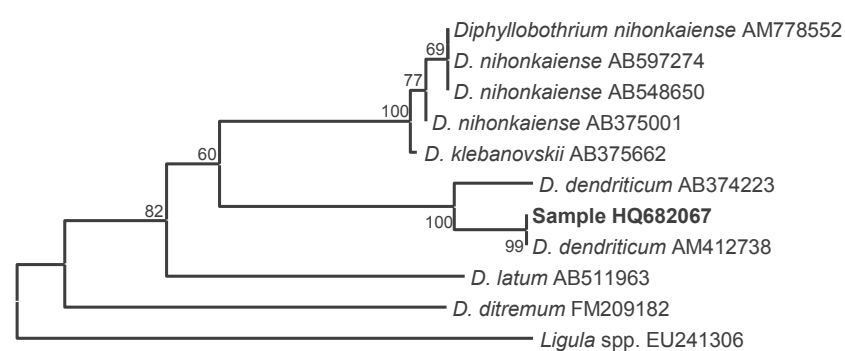

0.01

The tree is based on cytochrome c oxidase subunit 1 (cox1) sequence fragments of $375 \mathrm{bp}$. The 'sample' refers to the sequence of the unknown Diphyllobothrium spp. affecting the patient. GenBank accession numbers of all the sequences used to construct the tree are indicated. On the tree nodes, Kimura-2 parameters bootstrap values $>50$ for 500 replicates are shown.

and leaving to cook for one minute before serving. According to his mother, the patient enjoyed picking pieces of uncooked fish during the preparation of the meal. Short before travelling to south-east Asia, the patient consumed poorly cooked perch fillets (Perca fluviatilis) fished in the Leman lake in a restaurant near home. He also ate sushi in Switzerland one week before tapeworm segments were noticed.

Aquatic birds (especially Laridae) are usually the definitive hosts of $D$. dendriticum, while humans are only occasionally infected. According to literature, the incubation period of $D$. dendriticum in herring gulls (Larus argentatus) lasts from five to 20 days [17]. In humans, Diphyllobothrium plerocercoids generally develop into mature adults in two to six weeks [2].

Based on these observations, the source of the patient's infection might be either salmon from Norway, unknown fish from Asia or perch from Switzerland. However, because the presence of $D$. dendriticum in perch has not been documented so far, it is unlikely that the perch meal was the source of infection. The sushi meal in Switzerland can be excluded because the symptoms were already present at that time.

In the last two decades, diphyllobothriasis has shown a recrudescence in a number of European countries, especially in the subalpine lakes region [2]. The use of molecular methods also showed the presence of allochthonous $D$. nihonkaiense and $D$. dendriticum in France, Switzerland, Finland and the Czech Republic (Table). Except for two cases of $D$. dendriticum diagnosed in Switzerland [4] and the Czech Republic [18] that were probably acquired abroad (Norway, Alaska or Canada), most of the documented infections were locally acquired, attributed to imported salmons.

Susceptible intermediate hosts for $D$. dendriticum such as copepods (Eudiaptomus and Cyclops species [19]) and fish (Oncorhynchus mykiss, Salmo trutta, Coregonus clupeaformis, C. albula, C. lavaterus [19-21]) are known to be present in Switzerland. This would theoretically allow the introduction and the autochtonous transmission of the parasite. This colonisation potential emphasises the need for correct identification of Diphyllobothrium species involved in clinical cases of infection.

Interestingly, in the two Swiss cases due to $D$. dendriticum, the molecular investigation was undertaken because of the unusual shape of some segments.

The transmission of Diphyllobothrium plerocercoids may be prevented by freezing fish at $-20{ }^{\circ} \mathrm{C}$ for one to seven days, depending on its thickness. The Swiss law [22] provides that it is forbidden to sell any kind of fresh fish products (both local and imported) intended to be consumed raw or semi-raw, unless they have been stored at a temperature not higher than $-20^{\circ} \mathrm{C}$ for a least 24 hours. However, it has been demonstrated that this rule is not always followed properly [23], and of course there is no control of food bought abroad by individuals for personal use. Therefore cooking at $55^{\circ} \mathrm{C}$ or more, for at least $5 \mathrm{~min}$, remains the most reliable way to prevent transmission of parasitic worms possibly present in fresh fish [2].

\section{Conclusion}

A correct diagnosis has become crucial to evaluate the distribution of human-infecting Diphyllobothrium species, as well as their fish hosts, and to prevent the spread of allochthonous parasites in aquatic environments. Due to the difficulties in discriminating the different Diphyllobothrium taxa by morphological characters, molecular analysis has proven to be fundamental to identify these helminths at the species level. A cheap and rapid molecular test based on multiplex PCR with partial cytochrome $c$ oxidase subunit 1 (cox1) gene, without the need of sequencing, was recently developed for the differential identification of the most common species infecting humans [24]. In case of atypical specimens of proglottids and eggs and/or specimens derived from patients who have been abroad, this test could be used to verify the parasite's identity. Improving the diagnosis of Diphyllobothrium parasites would help to monitor the distribution of species in Europe and trace the source of infections, an important goal at a time when eating habits are changing, fish markets are globalising and climate is changing [25]. 


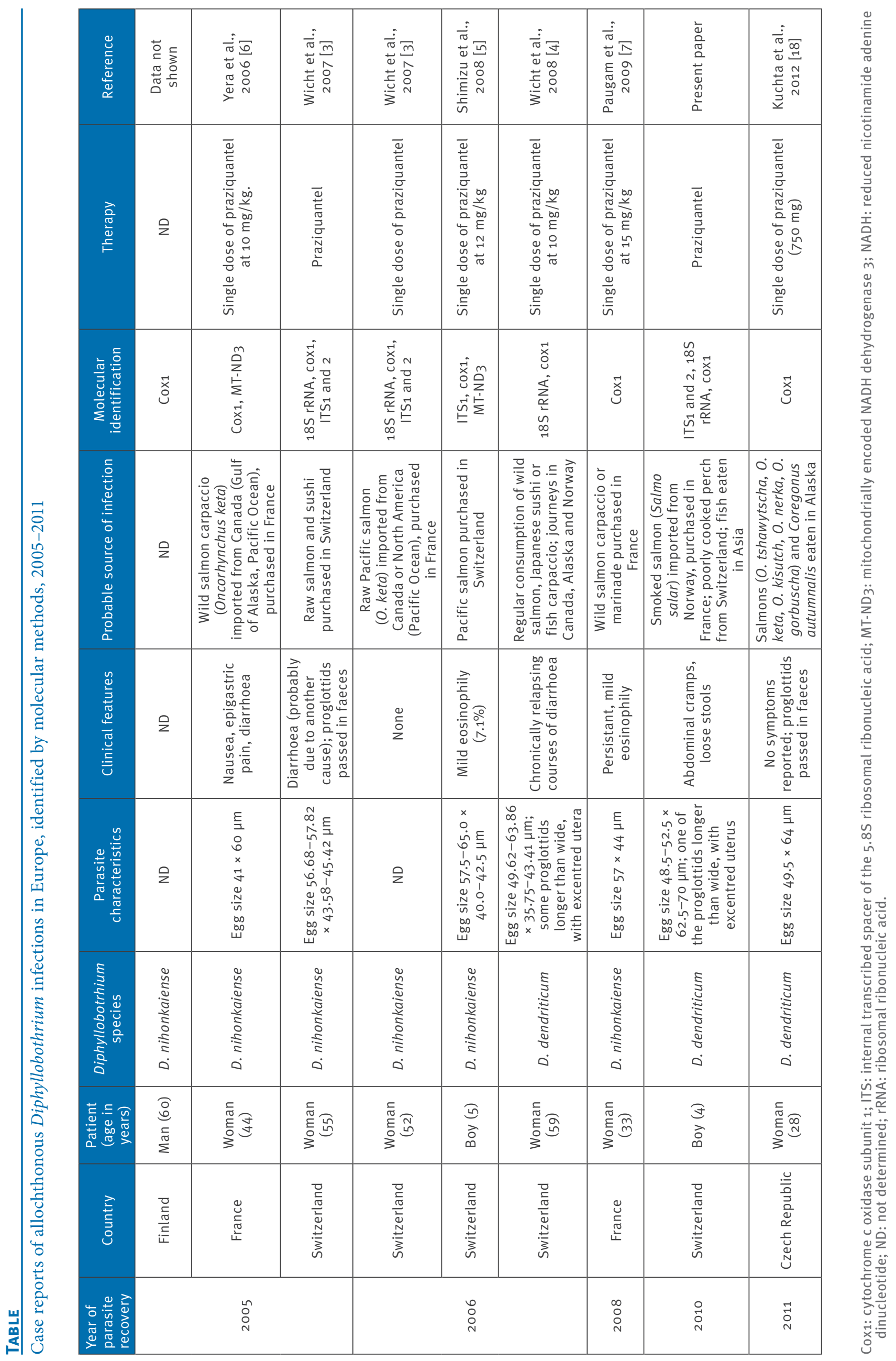




\section{Acknowledgments}

We gratefully thank the patient's mother, who gave spontaneous and detailed information on the family eating habits, the probable sources of infection and her cooking recipes. Thanks are also due to Seppo Meri (Department of Bacteriology and Immunology, University of Helsinki, Finland) for providing the specimen of $D$. nihonkaiense found in Finland.

\section{References}

1. von Bonsdorff B. Diphyllobothriasis in man. New York: Academic Press; 1977.

2. Scholz T, Garcia HH, Kuchta R, Wicht B. Update on the human broad tapeworm (genus Diphyllobothrium), including clinical relevance. Clin Microbiol Rev. 2009;22(1):146-60.

3. Wicht B, de Marval F, Peduzzi R. Diphyllobothrium nihonkaiense (Yamane et al., 1986) in Switzerland: first molecular evidence and case reports. Parasitol Int. 2007;56(3):195-9.

4. Wicht B, de Marval F, Gottstein B, Peduzzi R. Imported diphyllobothriasis in Switzerland: molecular evidence of Diphyllobothrium dendriticum (Nitsch, 1824). Parasitol Res. 2008;102(2):201-4.

5. Shimizu H, Kawakatsu H, Shimizu T, Yamada M, Tegoshi T, Uchikawa R, et al. Diphyllobothriasis nihonkaiense: possibly acquired in Switzerland from imported Pacific salmon. Intern Med. 2008;47(14):1359-62.

6. Yera H, Estran C, Delaunay P, Gari-Toussaint M, DupouyCamet J, Marty P. Putative Diphyllobothrium nihonkaiense acquired from a Pacific salmon (Oncorhynchus keta) eaten in France; genomic identification and case report. Parasitol Int. 2006;55(1):45-9.

7. Paugam A, Yéra H, Poirier P, Lebuisson A, Dupouy-Camet J. Bothriocéphalose à Diphyllobothrium nihonkaiense: un nouveau risque lié à la consommation de saumon [Diphyllobothrium nihonkaiense infection: a new risk in relation with the consumption of salmon]. Presse Méd. 2009;38(4):675-7. French.

8. Rommel M, Eckert J, Kutzer E, Körting W, Schnieder T, editors Veterinärmedizinische Parasitologie. 5th edition. Berlin: Paul Parey Verlag; 2000. German.

9. Rukhadze, Blajin. On a method for staining flukes and tapeworm segments as whole microscopical preparations. J Trop Med Hyg. 1929;33:342-5.

10. Luton K, Walker D, Blair D. Comparisons of ribosomal internal transcribed spacers from two congeneric species of flukes (Platyhelminthes: Trematoda: Digenea). Mol Biochem Parasitol. 1992;56(2):323-7.

11. Mariaux J. A molecular phylogeny of the Eucestoda. J Parasitol. 1998;84(1):114-24.

12. Bowles J, Blair D, McManus DP. Genetic variants within the genus Echinococcus identified by mitochondrial DNA sequencing. Mol Biochem Parasitol. 1992;54(2):165-73.

13. Altschul SF, Gish W, Miller W, Myers EW, Lipman DJ. Basic local alignment search tool. J Mol Biol. 1990;215(3):403-10.

14. Thompson JD, Higgins DG, Gibson TJ. Clustal W. improving the sensitivity of progressive multiple sequence alignment through sequence weighting, position-specific gap penalties and weight matrix choice. Nucleic Acids Res. 1994;22(22):4673-80.

15. Tamura K, Dudley J, Nei M, Kumar S. MEGA4: Molecular Evolutionary Genetics Analysis (MEGA) software version 4.0. Mol Biol Evol. 2007;24(8):1596-9.

16. Schmidt GD. How to know the tapeworms. Dubuque: WMC Brown Comp, Publishers; 1970.

17. Pronin NM, Timoshenko TM, Sanzhieva SD. Dynamics of egg production of the cestode Diphyllobothiurm dendriticum (Nitzsch, 1824) (Cestoda: Pseudophyllidea) and the concept of fecundity in helminths. Folia Parasitol (Praha). 1989;36(1):49-57.

18. Kuchta R, Wicht B, Ditrich 0 , Kubáčková P. Rare species of human broad tapeworms (Diphyllobothrium) in Europe. Oral presentation presented at: Xth Czech and Slovak Parasitological Days; 2012 May 28-June 1; Brno, Czech Republic.

19. Rahkonen R, Aalto J, Koski P, Särkkä J, Juntunen K. Cestode larvae Diphyllobothrium dendriticum as a cause of heart disease leading to mortality in hatchery-reared sea trout and brown trout. Dis Aquat Org. 1996;25:15-22.
20. Dick TA, Poole BC. Identification of Diphyllobothrium dendriticum and Diphyllobothrium latum from some freshwater fishes of central Canada. Can J Zool. 1985;63(1):196-201.

21. Dolezel, MC, Crompton DWT. Platyhelminth infections in powan, Coregonus lavaretus (L.), from Loch Eck and Loch Lomond, Scotland. Helminthologia. 2000;37(3):147-52.

22. Ordonnance du Département Fédéral de l'Intérieur sur l'hygiène (OHyg) du 23 novembre 2005 (état le 1er novembre 2010) $n^{\circ} 817.024 .1$, Art. 42 [Ordinance of the Federal Department of Home Affairs on Hygiene of 23 November 2005 (as of 1 November 2010) No. 817.024.1, Art. 42]. French. Available from: http://www.admin.ch/ch/f/rs/8/817.024.1.fr. pdf

23. Wicht B, Zali O. Contrôle parasitologique des poissons vendus dans les restaurants genevois. [Checking fish sold in Geneva restaurants for parasites]. Geneva; Service de la consommation et des affaires vétérinaires. Sep 2007-0ct 2008. p. 13. French.

24. Wicht B, Yanagida T, Scholz T, Ito A, Jiménez JA, Brabec J. Multiplex PCR for differential identification of broad tapeworms (Cestoda: Diphyllobothrium) infecting humans. J Clin Microbiol. 2010;48(9): 3111-6.

25. Torres P, Cuevas C, Tang M, Barra M, Franjola R, Navarrete $\mathrm{N}$, et al. Introduced and native fishes as infection foci of Diphyllobothrium spp. in humans and dogs from two localities at lake Panguipulli in southern Chile. Comparative parasitology. 2004;71(2):111-7. 